\title{
Modelling and Performance Analysis for a PV System Based MPPT Using Advanced Techniques
}

\author{
Eid A. Gouda, Mohamed. F. Kotb, and Dina A. Elalfy
}

\begin{abstract}
The produced power from Photovoltaic system is varied and its efficiency is severely affected by many factors such as irradiance and ambient temperature. To obtain a competent system with maximum benefits, the tracking of the maximum power point became mandatory. This paper presents an efficient design of maximum power point tracking "MPPT" for PV system control using three advanced techniques; PSO, Perturb- and-observe (P\&O) and Incremental Conductance (I_C). The PV system based MPPT has been modelled and simulated using MATLAB/SIMULINK. The results are studied, analyzed and compared to the three proposed algorithms. PSO proved higher tracking power, lower power loss, high tracking speed, less time and minor oscillation than the other two techniques.
\end{abstract}

Index Terms-Maximum power point tracking, Photovoltaic system, Particle Swarm Optimization, Perturb- and-observe. Incremental Conductance

\section{INTRODUCTION}

The renewable energy sources are grown up and became a reliable and clean alternative to the conventional fuel to avoid its drawbacks. These types of resources became the most required source in the networks as its demand reaches from $20 \%$ to $25 \%$ along the last 20 years [1]. Most of modern countries realized the importance of PV systems and invest more and more money utilizing this type of energy every year [2], [3]. The solar arrays system efficiency changes due to the nonlinear characteristics of current and power against voltage of the PV system, solar radiation, atmospheric temperature and the nature of the connected load [4]. The discrepancy between the load characteristics and the delivered maximum power points (MPPs) of the PV module can be solved by Maximum power point tracking (MPPT) to ensure optimal utilization of solar cells [5].

There are many methods to develop and implement (MPPT) [4, 7-19]. The methods vary in complexity, sensors required, convergence speed, cost, range of effectiveness, implementation hardware and popularity in addition to other respects [7]. Hill Climbing is the most common technique that takes steps over the $\mathrm{p}-\mathrm{v}$ characteristic to find out the MPP [14]. Many algorithms used this technique as the rate of change of power with respect to voltage " $\mathrm{dP} / \mathrm{dV}$ " Feedback Control, Incremental Conductance "I_C" and the Perturb \&

Published on January 28, 2019.

Eid A. Gouda is with the Department of Electrical Engineering, Faculty of Engineering, Mansoura University, 35516 Mansoura, Egypt (e-mail: eid.gouda@yahoo.fr)

Mohamed. F. Kotb is with the Department of Electrical Engineering, Faculty of Engineering, Mansoura University, 35516 Mansoura, Egypt (email: mohamadfawzi@gmail.com)
Observe $(\mathrm{P} \& \mathrm{O})$ algorithm which is the most widely used. The

$\mathrm{P} \& \mathrm{O}$ perturbs the duty cycle that controls the power converter to take steps over the $\mathrm{p}-\mathrm{v}$ characteristic leading to obtain the MPP [12]. The system is going to oscillate around the MPP. Originally, the perturbation step size has been reduced with fixed value to minimize the oscillation but this led to slow down the tracking speed to get the MPPT. To overcome this disadvantage, a variable perturbation size that gets smaller towards the MPP are designed [4, 11, and 18]. The rapidly changing of atmospheric conditions may cause failure to Hill climbing methods. Modified $\mathrm{P} \& \mathrm{O}$ method is used to track MPP under irradiance sudden changes [20]. Three-point weight method is used and the actual power point is compared with the two preceding readings before a decision of the perturbation sign is decided. The derivative of the power with respect to the voltage is the base of the $\mathrm{dP} /$ $\mathrm{dV}$ algorithm. The power and its derivative is calculated by measuring both the current and voltage. The fact that the derivative equals zero at the MPP is the base of the $\mathrm{dP} / \mathrm{dV}$ algorithm [14].

I_C method is based on the fact that the slope of the PV array power curve is zero at the MPP; positive on the left of the MPP, and negative on the right [8]. The increment size determines how fast the MPP is tracked. Bigger increments can achieve faster tracking but may increase the oscillation and the system might not operate exactly at the MPP. Another method utilizes the relation between short circuit current and the rated current at MPP or the relation between open circuit voltage with respect to rated voltage at MPP. The operating point which is close to the MPP is approximately calculated at various irradiance and temperature levels before using I_C method to exactly track the MPP in a second stage [21,22]. The periodically measuring of Open-Circuit Voltage "V $\mathrm{OC}_{\mathrm{OC}}$ requires momentarily shut down of the power converter which can cause temporary loss of power which considered disadvantage [23].

Current at the MPP " $I_{m p p}$ " has approximately linear relation with the $I_{s c}$ of the PV array as constant value $\mathrm{k}$ and known in array data sheet. The fractional Short-Circuit Current method calculates short circuit current at different atmospheric conditions, and by knowing the constant $\mathrm{K}$, the $I_{m p p} \quad$ can be approximately calculated [7]. $I_{s c}$ can be

Dina A. Elalfy is with the Department of Electrical Engineering, Faculty of Engineering, Mansoura University, 35516 Mansoura, Egypt (e-mail: dinaelalfy2002@gmail.com) 
measured using a current sensor by adding additional switch to the power converter to periodically short the PV array. This increases the number of components and cost.

In this paper, the PSO controller technique is presented as robust technique enables MPP tracking of the PV panel system. The proposed technique is compared to other classic tracking algorithms; the Perturb \& Observe (P\&O) and Incremental Conductance (incCond) methods. A good precision with reducing calculation time is achieved with a low-cost microcontroller [23, 24].

The principle, operation and characteristics of the PV cell is discussed in section II. In section III the mathematical model of the ideal PV cell and also the practical PV cell will be shown. Finally the simulation model developed using MATLAB and practical results will be presented in section IV. The paper will be finished by conclusion.

\section{PRoblem Statement}

The efficiency of a solar cell is very low (4\%-15\%); $15 \%$ for monocrystalline silicon cells; $12 \%$ for multi-crystalline silicon cells and $4 \%$ for polymer and organic pv cells. There are many factors affecting the efficiency of PV panels such as the atmospheric conditions (ambient temperature, irradiance, dirt/dust,...etc.) [25].

A PV cells energy conversion efficiency " $\eta$ ", is the percentage of maximum power point, $P_{\max }$ divided by the input light irradiance

$\eta^{\prime}=\frac{P_{\max }}{P_{\text {in }}}=\frac{\text { maximum } o / p \text { power }}{\text { incident radiation } \text { power }}$

(1)

$$
\eta=\frac{I_{m} * V_{m}}{P_{\text {in }}}
$$

\section{MPPT TRACKING TECHNIQUES}

There are a lot of methods to increase and enhance the efficiency of solar module. Maximum Power Point Tracking "MPPT" is one of these methods. The P-V characteristic curve exhibits a maximum power point "MPP" that varies nonlinearly with varying of the environmental condition, namely temperature and solar insulation which pose a challenge for the tracking algorithm

\section{A. Perturbation and Observation Technique $(P \& O)$}

The perturb \& observe "P\&O" algorithm, also known as the "hill climbing" method is a MPPT controller based on the voltage perturbation Vpv. The DC-DC converter signal directly affected by the perturbation coming from increasing or decreasing the amplitude around initial value by low quantity. Observing and analyzing the change of duty cycle after the perturbation, it will lead eventually to enhance the output power duty cycle of PV module [10].

P\&O algorithm is well known by its simplicity and easy implementation, so it's widely used. From the flow chart of $\mathrm{P} \& \mathrm{O}$ algorithm fig. (1), it can be noticed that when $\Delta \mathrm{P}>0$ the solution is rightly moving to MPP and slight increment of the perturb in the same direction will lead to a closer MPP. When $\Delta \mathrm{P}<0$, this means we are moving away from MPP and perturb increment must be reversed to move back toward MPP.

The duty cycle is to be changed after a set amount of time, then the $\mathrm{P} \& \mathrm{O}$ algorithm checks the previously measured input power and voltage. Duty cycle " $\mathrm{D}$ " is decreased to move closer to the peak power if the newly measured input power is greater than the previously measured input power and the new input voltage is greater than the old input voltage. The algorithm increases $D$ if the input voltage was less than previously measured and if it has greater input power. D decreases to converge to an MPP if the new power measured is less than previously measured and the new voltage is greater than the old voltage while the algorithm decreases D if the power and voltage are less than previously measured. Although the implementation of $\mathrm{P} \& \mathrm{O}$ algorithm simple and easy, its efficiency is limited. The operating point oscillates around MPP because it can't be known when MPP is reached and that will slightly reduce PV efficiency under constant irradiance condition [9]. The rapid change in atmospheric conditions will show erratic behavior in the operation of PV system and can affect MPPT efficiency.

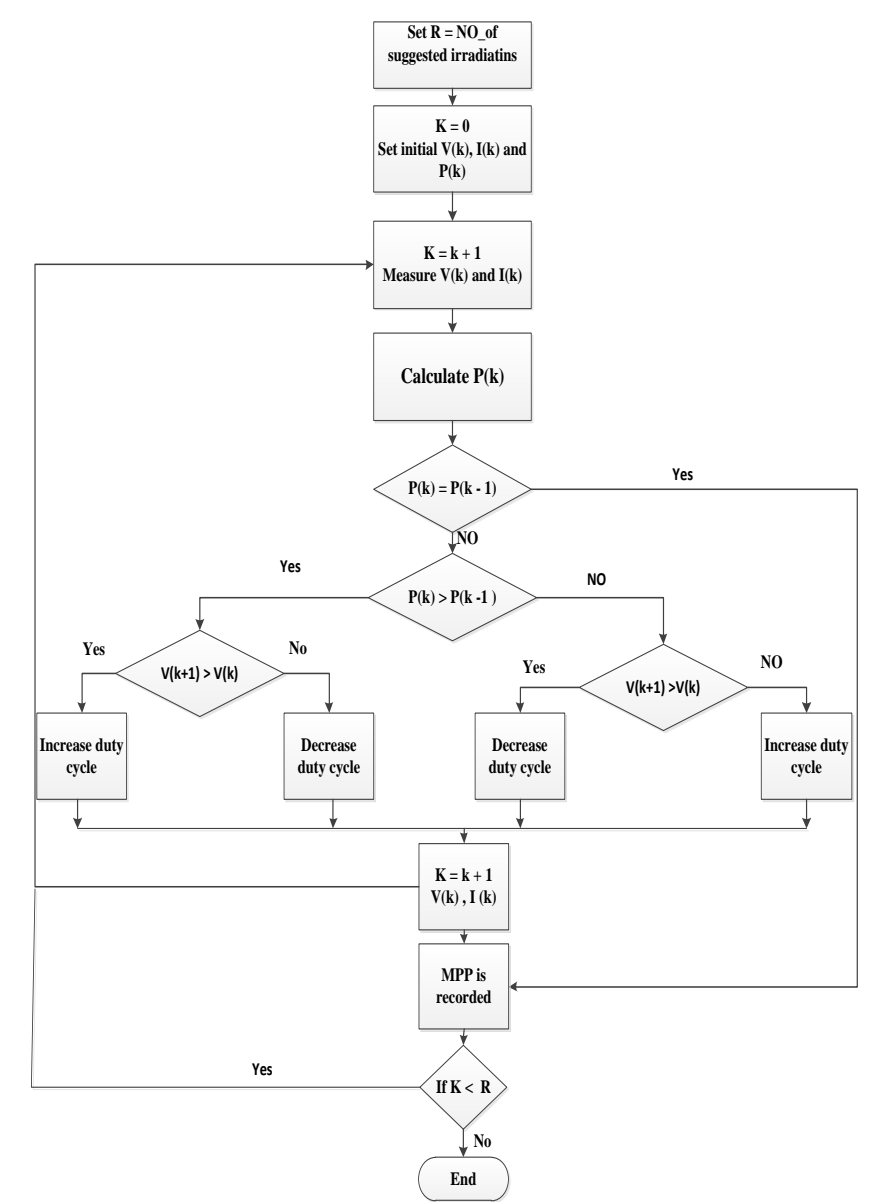

Fig (1) Flowchart of the $\mathrm{P} \& \mathrm{O}$ algorithm

\section{B. Incremental Conductance Technique (I_C)}

The erratic behavior in PV system due to rapid changing in atmospheric conditions when using $\mathrm{P} \& \mathrm{O}$ algorithm is solved by using Incremental Conductance (IncCond) algorithm. The slope of the PV array power curve is zero at the MPP as in figure (2), positive on the left and negative on the right $[8,11]$, the IncCond algorithm depends on the previous fact as follows: - 


$$
\left.\begin{array}{rr}
\frac{d P}{d \mathrm{~V}_{\mathrm{pv}}}=0 & \text { at MPP } \\
\frac{d P}{d \mathrm{~V}_{\mathrm{pv}}}>0 & \text { left to MPP } \\
\frac{d P}{d \mathrm{~V}_{\mathrm{pv}}}<0 & \text { right to MPP }
\end{array}\right\}
$$

Since

$\frac{d P}{d V}=\frac{d(I V)}{d V}=I+V \frac{d I}{d V} \sim I+V \frac{\Delta I}{\Delta V}$

Eq. (4) Can be rewritten as

$$
\left.\begin{array}{rr}
\frac{\Delta I_{p v}}{\Delta V_{p v}}=-\frac{I_{p v}}{V_{p v}} & \text { at MPP } \\
\frac{\Delta I_{p v}}{\Delta V_{p v}}>-\frac{I_{p v}}{V_{p v}}, & \text { left of MPP } \\
\frac{\Delta I_{p v}}{\Delta V_{p v}}<-\frac{I_{p v}}{V_{p v}}, & \text { right of MPP }
\end{array}\right\}
$$

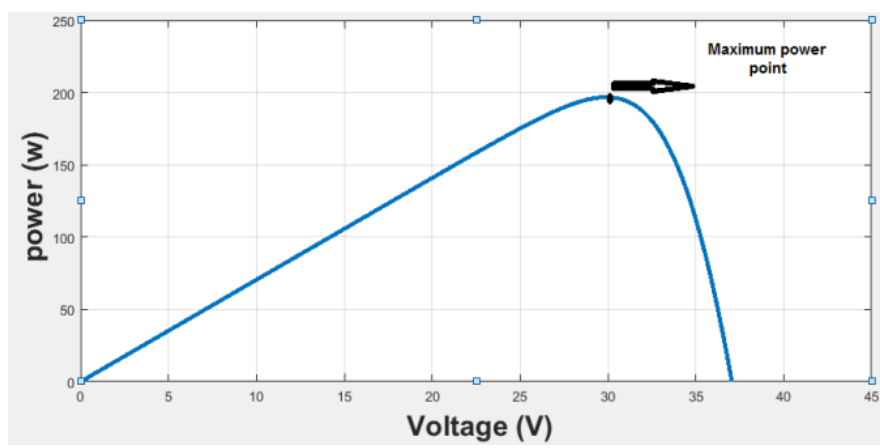

Fig (2). Characteristic PV array power curve.

Incremental Conductance algorithm uses the incremental measurements based on the change in conductance of the photovoltaic array. From flow chart shown in figure (3), the MPP can easily be known by comparing the instantaneous conductance $\left(\mathrm{I}_{\mathrm{pv}} / \mathrm{V}_{\mathrm{pv}}\right)$ to the incremental conductance $\left(\Delta \mathrm{I}_{\mathrm{pv}}\right.$ $\left(\Delta \mathrm{V}_{\mathrm{pv}}\right)$. When atmospheric conditions changes, a corresponding variation in $\Delta \mathrm{I}$ will be noticed. $\mathrm{PV}$ array is forced to operate at VMPP and considered as reference voltage " $V_{\text {ref }}$ " and can be calculated. Once MPP is reached with the calculated $V_{\text {ref, }}$, the operating of the PV array stays working at this point unless another change in both atmospheric conditions and $\mathrm{V}_{\text {ref }}$ to track the new MPP.

\section{Particle Swarm Optimization}

In 1995, Eberhart and Kennedy developed an intelligence optimization theory called Particle swarm optimization (PSO) [26]. The foraging behavior of birds and fish schooling was the inspiration of the basic concept of this algorithm, and this concept can reduce the search and optimization problems better than the conventional ones. PSO can easily determine each individual particle current position, current velocity, and personal best position in search space by maintaining a swarm of particles. Each particle represents a potential solution in the swarm and determines the required parameters that maximizes or minimizes the objective function in a given search space. The personal best position Pbest $_{i}$ corresponds to the position in search space where particle has the largest value as determined by the objective function " $F$ " considering a maximization problem. The global best position is the highest position value amongst all the personal best which is denoted by gbest [27]. The personal and global best values are updated and defined respectively using the following equations (6) to (8)

$$
\begin{aligned}
& \text { Pbest }_{i}=S_{i}^{k} \\
& F\left(S_{i}^{k}\right)>F\left(\text { Pbest }_{i}\right)
\end{aligned}
$$

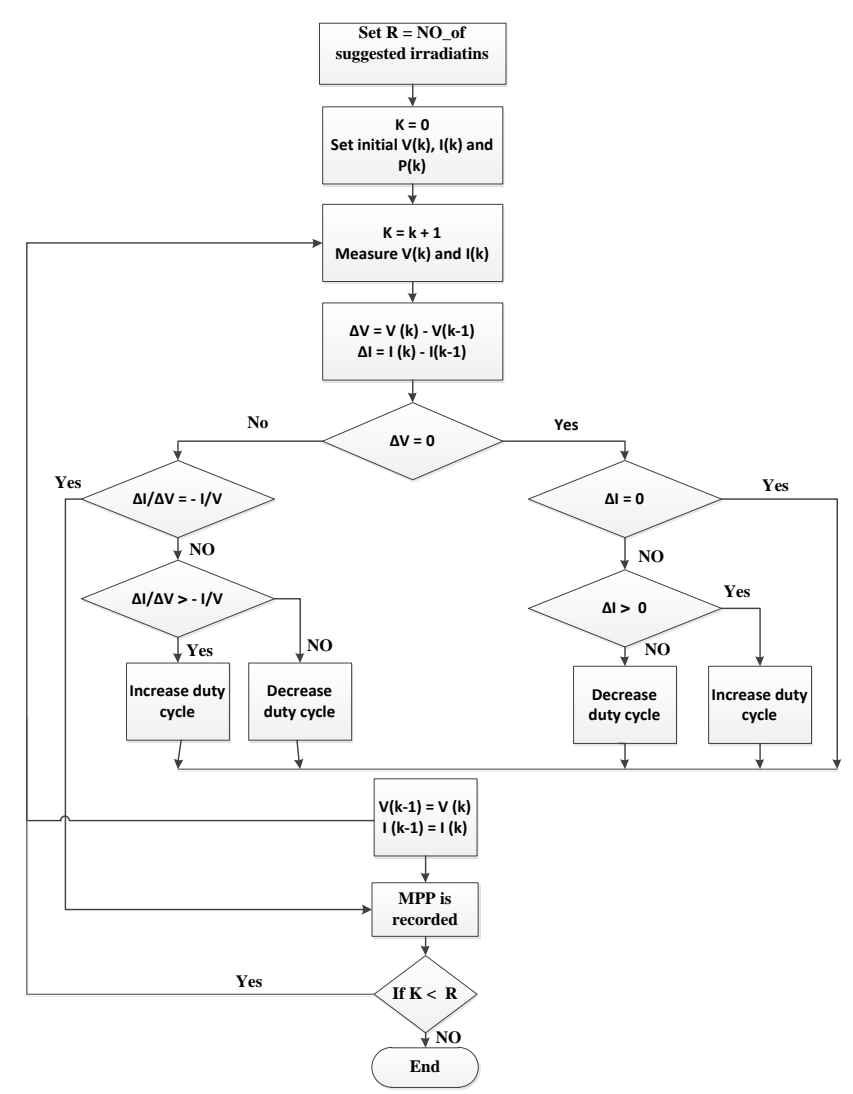

Fig. (3). Incremental Conductance algorithm

The objective function $\mathrm{F}$ which should be maximized. On the other hand, the best position discovered by any of the particles in the entire swarm is the global best position.

Gbest $=\max \left(\right.$ Pbest $\left._{i}\right)$

The particles Gbest and Pbest ${ }_{i}$ are saved by taking up the objective function's values during the optimization process. The next velocity and position of the candidate solution is determined by the basic PSO algorithm and can be given mathematically as:

$$
\begin{aligned}
v_{i}^{k+1}= & w \cdot v_{i}^{k}+r_{1} c_{1} \cdot\left(\text { Pbest }_{i}-x_{i}^{k}\right) \\
& +r_{2} c_{2} \cdot\left(\text { Gbest }-x_{i}^{k}\right)
\end{aligned}
$$

$x_{i}^{k+1}=x_{i}^{k}+v_{i}^{k+1}$

Where,

Pbest: Personal best position for the particle itself

Gbest: Global best position among all particles

$x i$ : The location of particle

$v i$ : The velocity of particle 
$r 1, r 2$ : Random numbers between $[0,1]$

$\mathrm{k}$ : number of iterations

$c 1, \quad c 2$ : Cognitive and social coefficient respectively (acceleration constants)

$\mathrm{W}$ : inertia weight that maintains a balance between the local and global search

As can be seen from equations $(9,10)$, the location and the velocity of the particle is updated in every iteration till reached the required value from the fitness function which is the maximum power of the PV module.

The PSO algorithm process can be explained as following:-

a. Define the random numbers $r_{1}$ and $r_{2}$, initialize the size of swarm, dimension of search space and maximum number of iterations.

b. Determine the current fitness of each particle in the population.

c. Define the particles by random initial positions and velocities.

d. Grade and calculate fitness value of each particle.

e. Determine the global best fitness value: current global best fitness $=\max$ (local best fitness).

f. Continue knowing the particle velocity and position at all time for next iteration. Know the current fitness of each particle: If current fitness > local best fitness, set local best fitness $=$ current fitness.

g. Find out the current global best fitness (current global best fitness $=\max ($ local best fitness)): If current global best fitness > global best fitness, then global best fitness= current global best fitness.

h. Achieving the maximum number of iterations is done by repeating Steps 6 and 7 or there is no improvement of the global best fitness value.

i. When the criterion is reached, the iterative algorithm is terminated.

\section{THE PROPOSED SYSTEM COMPONENTS}

The proposed system contains of PV array, connected to grid via a DC-DC boost converter and a three-phase, three level Voltage Source Converter (VSC) as simulated in fig (7).

\section{A. PV array}

The equivalent circuit of a PV cell is shown in Fig (4). It includes a current source, a diode, a series resistance and a shunt resistance [3, 28].

The PV array contains series and parallel PV cells. Greater high output voltage is accompanied with series connection while greater output current accompanied with parallel connection. These two principals of series and parallel cells are necessary to make PV systems [7]. It is essential to have knowledge on the mathematical modeling of a PV module to be implemented in a PV system.

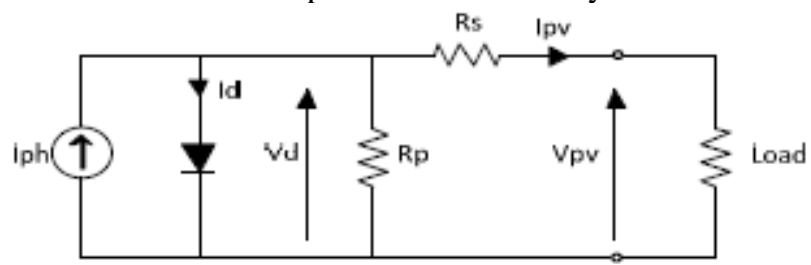

Fig (4) PV cell equivalent circuit.

The load current can be given as:

$I_{p v}=I_{p h}-I_{d}-I_{p}$
$I_{p v}=I_{p h}-I_{o}\left(e^{\frac{v_{p v}+R_{S} I p v}{v_{t} Q_{d} n_{s}}}-1\right)-\frac{v_{p v+R_{S} I p v}}{R_{p}}$

Where:

$v_{p v}=\mathrm{PV}$ module voltage $(\mathrm{V})$,

$I_{p v}=\mathrm{PV}$ module current (A),

$I_{p h}=$ light current $(\mathrm{A})$,

$I_{o}=$ diode reverse saturation current $(\mathrm{A})$

$Q_{d}=$ ideality factor,

$n_{s}=$ number of cells in series,

$R_{s}=$ series resistance includes the resistance of the material and contacts of the cell $(\Omega)$,

$R_{p}=$ shunt resistance results from current leakage through recombination at the $\mathrm{p}-\mathrm{n}$ junction or at the surface of the solar cell $(\Omega)$.

$v_{t}=\mathrm{kT} / \mathrm{q}$ is thermal voltage $(\mathrm{V}), \mathrm{k}$ is Boltzmann' $\mathrm{s}$ constant, $\mathrm{T}$ is the cell temperature, and $\mathrm{q}$ is the charge of an electron.

\section{B. Step-Up (Boost) Converter}

PV module has a non-linear characteristic differs according to solar radiation, temperature and the load condition. The variation in irradiance and temperature give each curve a different operating point at which the module can produce its maximum power. MPPT controller is required to overcome this problem by hunting only one global peak point. To operate the PV module at its MPP, a high efficiency DC-DC converter is required and that's the main role for MPPT system. The DC-DC converter is utilized as interface between PV module and the Load [5].

Fig. (5) Shows the schematic diagram of a step-up boost converter. This converter always gives output voltage greater than the input voltage. Isolating the output stage is done by turning the switch on which operates the diode in reversedbiased. Energy is supplied to the inductor from the input voltage source [29]. When the switch is off, energy is supplied from the inductor to output stage as well as the input source. In the continuous-conduction mode of operation, considering " $\mathrm{d}$ " as the duty ratio, the input-output relation is as follows:

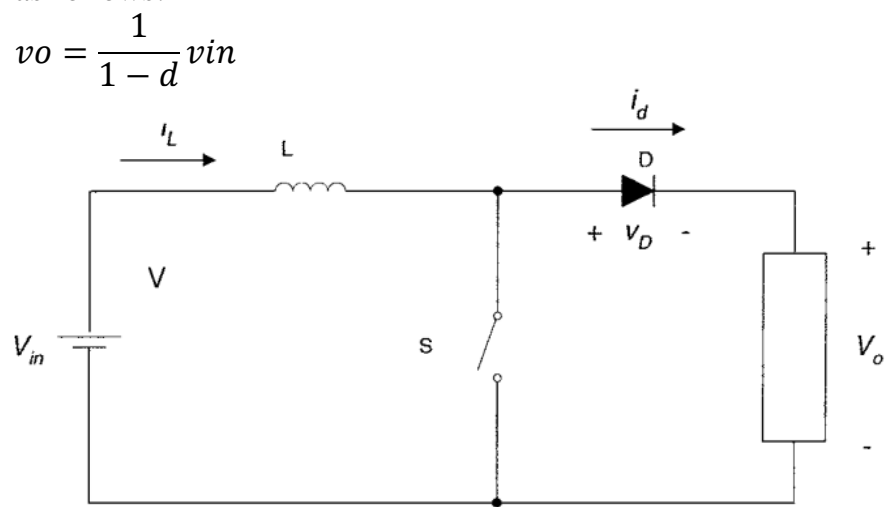

Fig (5) Step-up boost converter.

\section{Voltage Source Converter (VSC)}

The VSC converts the DC voltage to AC voltage and keep unity power factor. The VSC control system uses two control loops:

a. external control loop which regulates DC link voltage to $+/-250 \mathrm{~V}$ and

b. Internal control loop which regulates active $I_{d}$ and reactive $I_{q}$ current components of the grid. 


\section{System Data}

The system consists of a pv array which delivers 100 $\mathrm{kW}$ at $1000 \mathrm{~W} / \mathrm{m}^{2}$ irradiance, $5-\mathrm{kHz}$ dc-dc boost converter that increases voltage from $273 \mathrm{Vdc}$ (PV voltage) to $500 \mathrm{Vdc}$, the VSC converts $500 \mathrm{~V}$ dc to $260 \mathrm{v}$ ac and keeps the unity power factor. The harmonics produced from the VSC are filtered by $10-\mathrm{kvar}$ capacitor bank, three phase 100-kVA $260 \mathrm{~V} / 25 \mathrm{KV}$ coupling transformer and the utility grid as simulated in fig (7).

The photovoltaic module used in the simulation is sun power SPR - 305 -WHT. Table I contains specifications for one module.

Table (I): Photovoltaic Module Electrical Characteristics

\begin{tabular}{cc}
\hline Item & Data \\
\hline Maximum Power $\left(\mathrm{P}_{\max }\right)$ & $305 \mathrm{~W}$ \\
\hline Voltage at maximum power $\left(\mathrm{V}_{\mathrm{mp}}\right)$ & $54.7 \mathrm{~V}$ \\
\hline Current at maximum power $\left(\mathrm{I}_{\mathrm{mp}}\right)$ & $5.58 \mathrm{~A}$ \\
\hline Open-circuit voltage $\left(\mathrm{V}_{\mathrm{oc}}\right)$ & $64.2 \mathrm{~V}$ \\
\hline Short-circuit current $\left(\mathrm{I}_{\mathrm{sc}}\right)$ & $5.96 \mathrm{~A}$ \\
\hline
\end{tabular}

The photovoltaic array consists of 66 strings of 5 series connected sun power SPR - 305 -WHT modules, is simulated for different values of irradiance $\left(\mathrm{kW} / \mathrm{m}^{2}\right)$. Fig. (6) shows I$\mathrm{V}$ and $\mathrm{P}-\mathrm{V}$ characteristics of the array for different values of irradiance at constant temperature $\left(25^{\circ} \mathrm{C}\right)$.
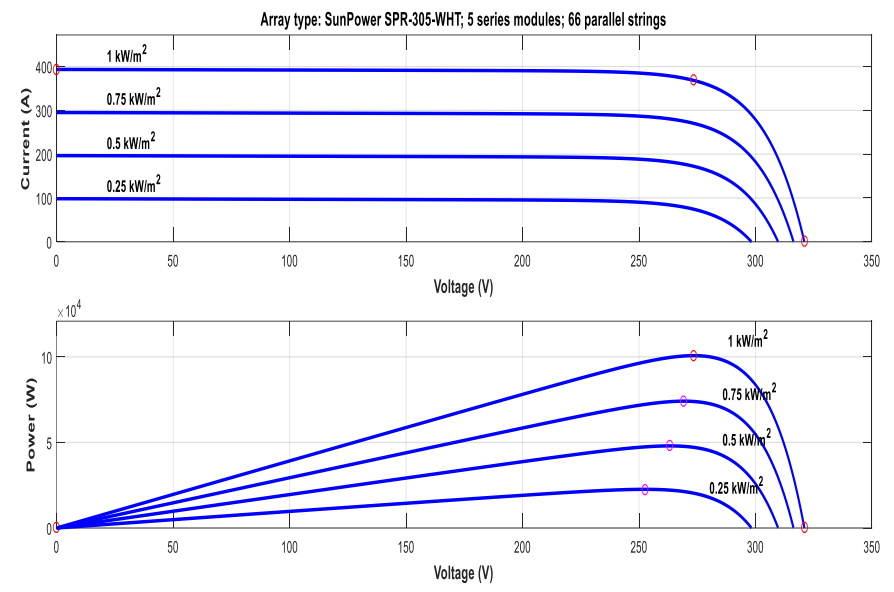

Fig (6) I-V and P-V Characteristics of PV array at $25^{\circ} \mathrm{C}$

DC-DC boost converter has a frequency of $5-\mathrm{kHz}$ with increasing voltage from PV natural voltage $(273.5 \mathrm{~V}$ DC at maximum power) to $500 \mathrm{~V} \mathrm{DC}$. Switching duty cycle is optimized by a MPPT controller that uses the 'Perturb \& Observe' technique and Incremental conductance.

The VSC converts the $500 \mathrm{~V}$ DC link voltage to $260 \mathrm{~V} \mathrm{AC}$ and keep unity power factor.

\section{APPliCATION AND SimULATION RESUlts}

The system model is simulated in MATLAB /SIMULINK. The pv array is connected to a signal builder which corresponds to irradiance signal that is rapidly changing taking the form of stairs. The MPPT controller is used to track maximum power point (MPP) by using two codes for P\&O and I_C and then they are compared with PSO controller. The output duty cycle is adjusted and controlled through DC-DC boost converter, VSC and through step down transformer.

\section{A. Simulation of PV Array Connected to Grid Using P\&O as MPPT Algorithm}

Maximum Power Point Tracking (MPPT) is implemented for the boost converter by means of a Simulink model using $\mathrm{P} \& \mathrm{O}$ algorithm. This MPPT system automatically varies the duty cycle in order to generate the required voltage to extract maximum power as shown in fig (7).

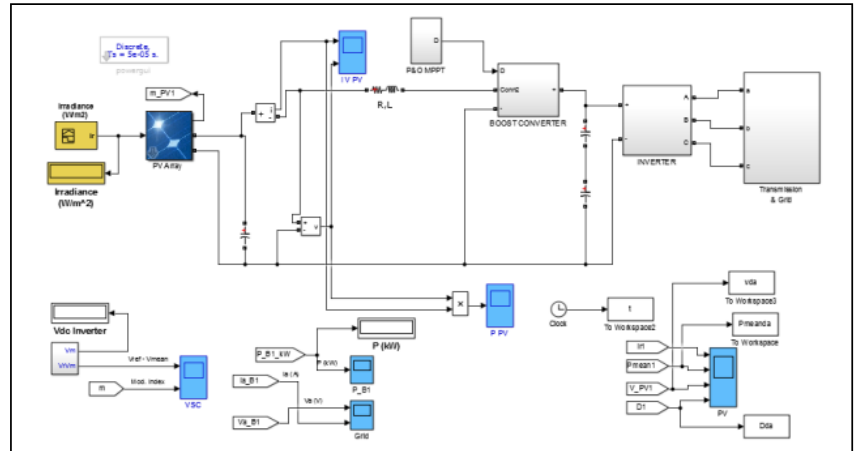

Fig (7) simulation system using $\mathrm{P} \& \mathrm{O}$ controller

Variable irradiance is applied with different step size of $\mathrm{W} / \mathrm{m}^{2}$. The irradiance is assumed 250, 500, 750 and 1000 $\mathrm{w} / \mathrm{m}^{2}$ in steps with time interval $0.5 \mathrm{sec}$ for each step as shown in figure (8).

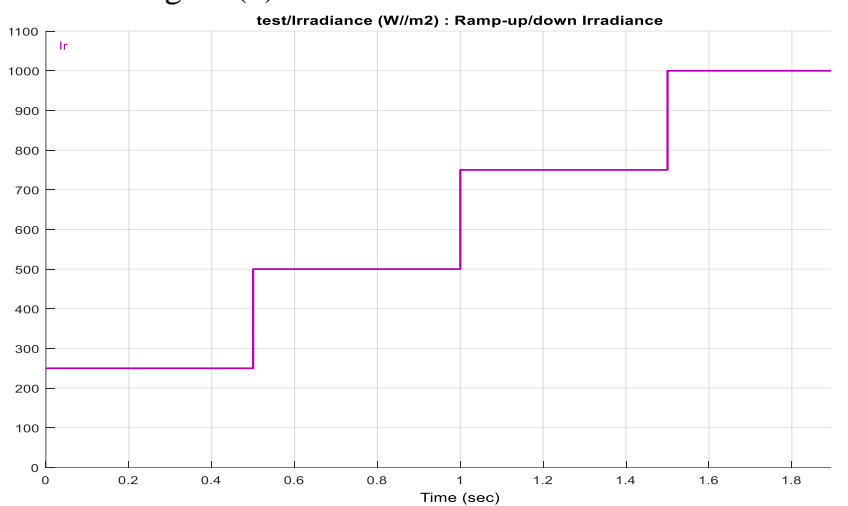

Fig (8) Irradiance at each step

The output power of PV module has been tracked and studied under different conditions of irradiance and the temperature is set at $25^{\circ} \mathrm{C}$. The increase in the irradiance results in increase in overall power of the solar PV panel as shown in fig (9).

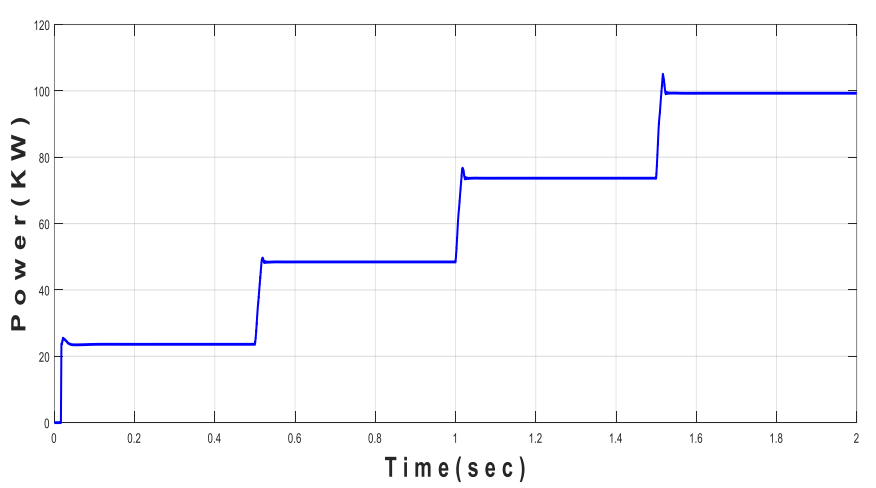

Fig (9) PV output power at each step using P\&O algorithm

The produced energy under the tracked power curve using $\mathrm{P} \& \mathrm{O}$ method is found equal to $120.9581 \mathrm{KWh}$. 
The efficiency criterion $\eta_{m p p t}$ of a MPPT controller defined by:

Efficiency at MPPT $=\frac{p_{\text {out }}(\text { tracked })}{p_{\max }(\text { rated })} * 100 \%$

The resultant efficiency found : $\eta_{m p p t}=98.77 \%$

\section{B. Simulation of PV Array Connected to Grid Using I_C as MPPT Algorithm}

This MPPT system automatically varies the duty cycle in order to generate the required voltage to extract maximum power by means of the I_C controller as shown in fig (10).

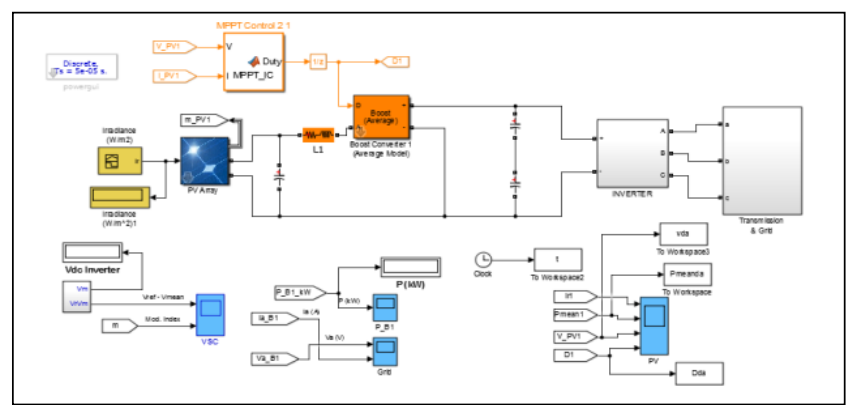

Fig (10) simulation system using I_C controller

The output power using I_C algorithm with varying the irradiance as per figure (8) at fixed temperature $\left(25^{\circ} \mathrm{C}\right)$ is shown in fig (11).

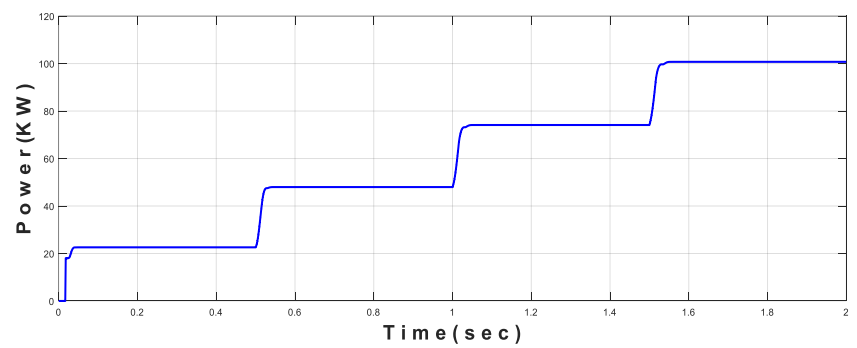

Fig (11) PV output power at each step using I_C algorithm

The energy under the tracked power curve using I_C method is found equal to $121.2772 \mathrm{KWh}$ with effiency

$$
\eta_{m p p t}=98.96 \% \text {. }
$$

\section{Simulation of PV Array Connected to Grid Using PSO controller as MPPT Algorithm}

PSO algorithm is implemented assuming PSO parameters as indicated in table (II)

Table (II) Parameters used for PSO algorithm

\begin{tabular}{cc}
\hline \hline parameters & value \\
\hline No of particles $(\mathrm{N})$ & 10 \\
No of dimensions $(\mathrm{D})$ & 1 \\
Maximum velocity $\left(V_{\max }\right)$ & 4 \\
No of iterations $\left(\right.$ Iter $\left._{\max }\right)$ & 2000 \\
Acceleration constant $1\left(c_{1}\right)$ & 2 \\
Acceleration constant $2\left(c_{2}\right)$ & 2 \\
Initial inertia weight $\left(w_{1}\right)$ & 0.9 \\
Final inertia weight $\left(w_{2}\right)$ & 0.4 \\
\hline
\end{tabular}

The energy under the tracked power curve using PSO method is found equal to $124.2423 \mathrm{KWh}$ with effiency

$$
\eta_{m p p t}=99.35 \% \text {. }
$$

The tracked power generated using the three methods is indicated in one figure (12). It can be noticed that PSO has almost zero steady state oscillation than P\&O and I_C and $\mathrm{P} \& \mathrm{O}$ has more oscillations around the MPP than the I_C.

Table (III) summarizes the comparison between the three methods at different irradiance in terms of Tracked Power, process time to reach MPP, power loss and efficiency of a MPPT controller. The time required to obtain the MPP is proportional to the tracking speed.

It's clear that PSO is better than P\&O and I_C techniques. The power generated when using the PSO technique was greater than $99 \%$ under all test conditions. It is noticed that PSO has higher efficiency, lesser power losses and higher accuracy than P\&O and I_C. Also, PSO has the highest tracking speed than I_C and P\&O with the lowest time among all of them.

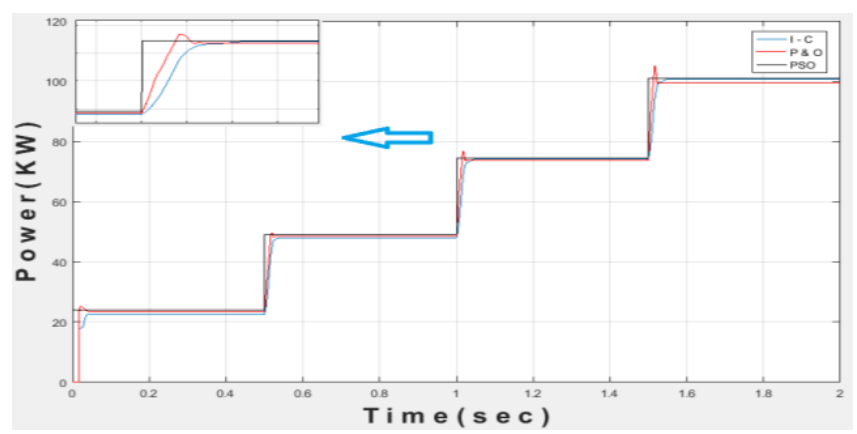

Fig (12): Tracked power using the three controllers P\&O, I_C and PSO.

Table (III): Comparison Between PSO, I_C and P\&O Algorithms at different Irradiance

\begin{tabular}{ccccc}
\hline \multirow{2}{*}{ Parameter } & \multirow{2}{*}{ IRR } & \multicolumn{3}{c}{ Method } \\
\cline { 3 - 5 } & & PSO & I_C & P\&O \\
\hline Tracked Power at & 250 & 23.46 & 22.56 & 22.19 \\
different IRR & 500 & 48.39 & 47.67 & 47 \\
(Kw) & 750 & 74.5 & 73.808 & 72.9 \\
& 1000 & 100.5 & 100.2 & 99.63 \\
\hline Process time to & 250 & 0.4 & 40 & 50 \\
reach MPP at & 500 & 0.5 & 29 & 38 \\
different IRR & 750 & 0.5 & 30 & 40 \\
(m sec) & 1000 & 0.3 & 34 & 34 \\
\hline \multirow{2}{*}{ Power loss at } & 250 & 22 & 60 & 75 \\
different IRR & 500 & 12 & 27 & 40.8 \\
(w) & 750 & 6 & 15 & 28 \\
\hline \multirow{2}{*}{ MPPT efficiency } & 1000 & 1 & 4.9 & 10.6 \\
at different IRR & 500 & 98.75 & 97.28 & 95.9 \\
$(\%)$ & 750 & 99.33 & 98.4 & 97.2 \\
& 1000 & 99.38 & 98.96 & 97.88 \\
\hline
\end{tabular}

\section{CONCLUSION}

The three advanced techniques PSO, Perturb- andobserve (P\&O) and Incremental Conductance (I_C) are utilized to simulate and model the PV system based MPPT. The best operation and performance of the MPPT controller for the three algorithms are studied and analyzed at different irradiance at constant temperature. By fine adjustment of the controlling parameters of PSO algorithm, it proved best results than the other two algorithms. PSO led to obtaining slightly higher tracked power (nearly $1 \mathrm{kw}$ more than the other two algorithms) for the different irradiance. Using of 
PSO, the power loss was reduced by nearly $55 \%$ to $60 \%$ compared to I_C and about $70 \%$ to $90 \%$ compared to P\&O at the different irradiance. Also, PSO raised the MPPT efficiency between $1 \%$ to $5 \%$ for the different irradiance compared to the other two algorithms. In addition, PSO could obtain the higher tracked power without oscillation around MPP in a very short time compared to the other two techniques. The execution time to reach MPPT was reduced to fraction of seconds against 30 to $50 \mathrm{msec}$. if the other techniques are used.

\section{REFERENCES}

[1] J. Selvaraj, N.A. Rahim,"Multilevel Inverter For Grid-Connected PV System Employing Digital PI Controller", IEEE Transactions On Industrial Electronics, 2009,vol. 56, No. 1, pp. 149-158

[2] J. Kondalaiah, I. Rahul," PHOTOVOLTAIC BASED HIGHEFFICIENCY SINGLE- INPUT MULTIPLE-OUTPUT DC-DC CONVERTER", International Journal of Computer Science and Mobile Computing, October- 2014,Vol.3 Issue.10, pg. 483-496.

[3] T. Salmi, M. Bouzguenda, A. Gastli and A. Masmoudi, "MATLAB/Simulink Based Modelling of Solar Photovoltaic Cell", INTERNATIONAL JOURNAL of RENEWABLE ENERGY RESEARCH, Vol.2, No.2, 2012.

[4] 4 M.A. Emad, S. Masahito, " Modified adaptive variable step-size MPPT based-on single current sensor", TENCON 2010 - IEEE Region 10 Conference, 21-24 November, pp. 1235-1240.

[5] 5 H. Rezk, A. M. Eltamaly, "A comprehensive comparison of different MPPT techniques for photovoltaic systems", Science Direct, Solar Energy 112,2015 , pp.1-11.

[6] A. H. EL-Din, S. S. Mekhamer and H. M. El-Helw ,"COMPARISON OF MPPT ALGORITHMS FOR PHOTOVOLTAIC SYSTEMS UNDER UNIFORM IRRIADIANCE BETWEEN PSO AND P\&O", October 2017, Vol.4, Issue.10.

[7] T. Esram, P. L. Chapman: "Comparison of Photovoltaic Array Maximum Power Point Tracking Techniques" IEEE Transaction on Energy Conversion, 2007, Vol. 22. No. 2, pp. 439-449.

[8] J. Patel1, V. sheth and G. Sharma, "DESIGN \& SIMULATION OF PHOTOVOLTAIC SYSTEM USING INCREMENTAL MPPT ALGORITHUM" ,International Journal of Advanced Research in Electrical, Electronics and Instrumentation Engineering, May 2013, Vol. 2, Issue 5.

[9] O. B. Belghith, L. Sbita and F. Bettaher ,"MPPT Design Using PSO Technique for Photovoltaic System Control Comparing to Fuzzy Logic and P\&O Controllers", Energy and Power Engineering, 2016.

[10] E. Koutroulis, F. Blaabjerg , "A New Technique for Tracking the Global Maximum Power Point of PV Arrays Operating Under PartialShading Conditions", IEEE journal of photovoltaics, April 2012,VOL. 2, NO. 2.

[11] B. A. Isaloo, P. Amiri "Improved Variable Step Size Incremental Conductance Mppt Method With High Convergence Speed For Pv Systems", Journal of Engineering Science and Technology ,2016,Vol. 11 , No. 4 , pp. $516-528$.

[12] A. Kumar, M. Kumar, D. H. Nagaraj, A. Singh, J. Prattapati, "Implementation of MPPT Algorithm for Grid Connected PV Module with IC and P\&O Methodv",International Journal of Electrical, Computer, Energetic, Electronic and Communication Engineering,2014, Vol:8, No:7.

[13] M. R.Hamzescu, S. Oprea, "Practical Guide to Implementing Solar Panel MPPT Algorithms", 2013 Microchip Technology Inc.

[14] S. Moring, A. Pols, "Maximum Power Point Tracking: Algorithm and Software Development", Delft University of Technology Faculty of EEMCS, June 27, 2012.

[15] A. K. Abdelsalam, A. M. Massoud, S. Ahmed and P. N. Enjeti, "HighPerformance Adaptive Perturb and Observe MPPT Technique for Photovoltaic-Based Micro grids", IEEE Transactions On Power Electronics, April 2011,VOL. 26, NO. 4.

[16] N. Femia, F. Petrone, G. Spagnuolo, "Predictive \& Adaptive MPPT Perturb and Observe Method", IEEE Transactions On Aerospace And Electronic Systems, July 2007,VOL. 43, NO. 3.

[17] N. Femia, G. Petrone, G. Spagnuolo and M. Vitelli, "Optimization of Perturb and Observe Maximum Power Point Tracking Method", IEEE Transactions On Power Electronics, July 2005, VOL. 20, NO. 4.

[18] N. S. D'Souza, L. A. Lopes and X. Liu, “An Intelligent Maximum Power Point Tracker Using Peak Current Control”, IEEE, 2005.

[19] V. R. Kota, M. N. Bhukya, "A Simple and Efficient MPPT Scheme for PV Module Using 2-Dimensional Lookup Table”, IEEE, 2016.
[20] Y. T. Hsiao and C. H. Chen, "Maximum power tracking for photovoltaic power system," in Conf. Record 37th IAS Annu. Meeting Ind. Appl. Conf., 2002, pp. 1035-1040.

[21] K. Irisawa, T. Saito, I. Takano, and Y. Sawada, "Maximum power point tracking control of photovoltaic generation system under non-uniform insolation by means of monitoring cells," in Conf. Record TwentyEighth IEEE Photovoltaic Spec. Conf., 2000, pp. 1707-1710.

[22] B. Bekker and H.J. Beukes, , "Finding an optimal PV panel maximum power point tracking method, IEEE, 2004.

[23] M. Mayatake , M. Veerachary , F. Toriumi ,"Maximum Power Point Tracking of Multiple Photovoltaic Arrays: A Particle Swarm Optimization Approach", IEEE Transactions on Aerospace and Electronic Systems, 2011, pp.367-380.

[24] K.Ishaque, Z.Salam, M. Amjad ,"An Improved Particle Swarm Optimization (PSO)-Based MPPT for PV with Reduced Steady-State Oscillation", IEEE Transactions on Power Electronics, 2012,pp.36273638 .

[25] M.E. Meral and F. Dinc, er, "A review of the factors affecting operation and efficiency of photovoltaic based electricity generation systems," Renewable and Sustainable Energy Reviews 15 , 2011, pp. $2176-2184$

[26] J. Kennedy and R. Eberhart, "Particle swarm optimization," Proceedings of IEEE International Conference on Neural Networks (ICNN'95), 1995,vol. 4, pp. 1942-1948.

[27] U. Rai1, "Modeling of Solar PV system under Partial Shading using Particle Swarm Optimization based MPPT," International Research Journal of Engineering and Technology (IRJET), Feb -2017.

[28] G. Celsa, G. Marco Tina, "Matlab/Simulink Model of Photovoltaic Modules/Strings under Uneven Distribution of Irradiance and Temperature", 2015 6th International Renewable Energy Congress (IREC).

[29] R. Wies, B. Satavalekar, and A. Agrawal, "Power Electronic Circuits and Controls".

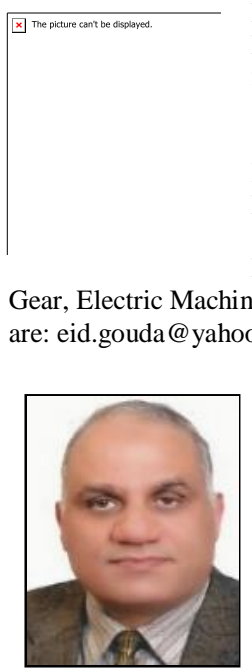

Eid Abdelbaki GOUDA was born in Domiatta, Egypt, on 1975. He received B.Sc. And M.Sc. Degree from electrical engineering Mansoura University in 1997 and 2004 respectively. He is completed his Ph.D at University Henri Poincaré of Nancy, the Groupe de Recherche en Electrotechnique et Electronique de Nancy, France in 2011. Now, he is associate professor at Electrical Department in faculty of Engineering, Mansoura University. $\mathrm{He}$ is interested in Magnetic Gear, Electric Machine Design/Control and Protection Systems. His E mails are: eid.gouda@yahoo.fr and eaidgoda@mans,edu.eg.

Mohamed F. Kotb was born in Monofia, Egypt, on 1960. He graduated from Mansoura University. $\mathrm{He}$ received M.Sc. and $\mathrm{PhD}$ Degree from Mansoura University in 1989 and 1998 respectively. He is a member of Electrical Department in faculty of Engineering, Mansoura University. He is interested in The Electrical Power System Analyses and application researches. He has wide experience with industry applications, consultations and International Training. Dr. Mohamed is member in IEEE. His $E$ mail is: mohamadfawzi@gmail.com. 